\title{
Investigation of Agricultural Biomass Residues in Liquefaction Process
}

\author{
Leite B. S., Ferreira D. J. O., Leite S. A. F., Bastos F. S., Lins V. F. C., and Castro B. T.
}

\begin{abstract}
The use of agricultural biomass residues as an alternative of fossil derivatives have been extensively investigated in the last years due to environmental concerns. In this context, the liquefaction appears as an alternative to use these renewable sources to produce green materials. The present work aims to synthesize polyols from the cassava peels (CP), lemon bagasse $(\mathrm{LB})$ and rice husk $(\mathrm{RH})$ in order to obtain biopolyols suitable to produce polyurethane foams and add value to these residues. Besides the production of the green foams, this work has also the objective to evaluate how composition of the biomass (e.g.: solid, lignin and holocellulose content) can be related to the process yield and the characteristics of the biopolyol (e.g: hydroxyl number). The polyols were synthesized from the biomass liquefaction, using crude glycerol as solvent (a by-product of biodiesel industry) and sulfuric acid as catalyst. The liquefaction was performed using an autoclave, operated at $125{ }^{\circ} \mathrm{C}$ and 1.84 atm. Liquefaction yield varied from 38 to $91 \%$, according to biomass and process parameters used. It was observed that $\mathrm{CP}$, which has the higher volatile solids content and the lower lignin plus holocellulose content, had the higher liquefaction yield. Polyol's hydroxyl number from RH had the lowest values and lower variation, according to process parameters. Liquefaction yield and hydroxyl number from LB presented great response to process parameters used.
\end{abstract}

Index Terms-Valorization, polyol, lignocellulosic, lignin.

\section{INTRODUCTION}

The uses of biomass and agricultural wastes as an alternative of fossil derivatives have been extensively investigated in the last years due environmental concerns. Several processes were developed in order to advance these renewable sources and generate green materials comparable to those petroleum-derived [1].

It is estimated that Latin America has the highest biomass potential, after considering food production and resource constraints [2]. Brazil is one of the most promising producers of biomass residues and has abundant renewable energy sources [3]. It is also one of the largest producers of citrus with a production of about 19 million tons in 2013. The juice

Manuscript received June 12, 2019; revised August 23, 2019.

Leite B. S. F., Leite S. A. F., and Bastos F. S. are with the Institute of Science and Technology, Universidade Federal de Viçosa (UFV- Campus Florestal), Florestal, MG, Brazil (e-mail: brennoleite@ufv.br, sibeleaugusta@ufv.br, fernando.bastos@ufv.br).

Ferreira D. J. O. and Lins V. F. C. are with Chemical Engineering at the Department of Chemical Engineering of the Federal University of Minas Gerais, Belo Horizonte, MG, Brazil (e-mail: chaada@gmail.com, vlins@deq.ufmg.br).

Castro B. T. is with Chemistry Universidade Federal de Viçosa (UFVCampus Florestal), Florestal, MG, Brazil (e-mail: bruno.tassicastro@gmail.com). industry makes use of only 40 to $50 \%$ of the fruit and its remainder is considered industrial residue [4].

Biomass liquefaction research is focused on the solvolysis of modified raw material at the early stage [5]. Among its products, bio-based polyols have suitable properties to produce polyurethane foams with comparable properties to the conventional ones. Liquefaction profitability dependents on the technology employed to alter the structure of lignocellulosic biomass and the feedstock used to produce the high value co-products. Most biomass liquefaction processes use petroleum-derived as biomass liquefaction solvents. The use of these fossil solvents increases the production cost and also contributes to the high carbon footprint of the polyols and polyurethanes from liquefaction process [6]. In this sense, several studies have shown that crude glycerol (co product of biodiesel production) can improve the properties of bio-based polyols and polyurethane (PU) foams derived from the liquefaction of lignocellulosic biomass [7]. Biomass products can significantly reduce greenhouse gases emission, compared to fossil-based products, although the maturity and economics of the processes and logistics are the main challenges for lignocellulosic biomass conversion [8].

Agricultural residues have large differences in their physical and chemical properties than wood. As a result, the optimum conditions that can be applied to the liquefaction of wood may be not suitable for the agricultural residues. Lemon bagasse, Rice husk and Cassava peels are a lignocellulosic residue combining cellulose, hemicelluloses and lignin and due to its characteristics it may be investigated for value-added chemicals productions [1], [9]-[13].

The aim of this work was to produce biopolyol from the lignocellulosic residues: lemon bagasse, rice husk and cassava peels and also to understand the influence of chemical composition and operation parameters on the liquefaction yield and hydroxyl number of three different biomass. Biomasses were characterized using Proximate Analysis, Lignin and Holocellulose Content and Nitrogen Total Kjeldahl. The polyols were synthesized from the biomass liquefaction, using crude glycerol as solvent and sulfuric acid as catalyst. The liquefaction was performed using an autoclave, operated at $125^{\circ} \mathrm{C}$ and $1.84 \mathrm{~atm}$. Biopolyols were characterized using Hydroxyl Number, functional groups, specific mass and viscosity.

\section{EXPERIMENTAL}

\section{A. Sampling}

The rice husk, cassava peels and lemon bagasse samples were collected between May and October of 2016 in the 
southeast region of Brazil (Florestal, Minas Gerais - Brazil). The samples were dried at $105{ }^{\circ} \mathrm{C}$ using an oven-dry until a constant weight was achieved. Then biomass cut in a knifle mill to get fibers of $0.5 \mathrm{~mm}$ length for future chemical and physical analyses, which were performed in duplicate. The crude glycerol used as liquefaction solvent, was kindly provided by Petrobrás (Usina Darcy Ribeiro - Montes Claros - MG, Brazil) as received. Sulfuric acid (Synth) was used as catalyst for this reaction. The reactants used to perform the hydroxyl number of the polyols produced were 1,4-dioxane (Synth), imidazole (Synth), phtalic anydride (Synth) and sodium hydroxide (Synth). Polyurethane foams were synthesized using the polyols produced from lemon bagasse, isocyanate (Desmodur $44 \mathrm{~V} 20$ of Bayer), surfactant (Tegostab 8460 supplied by Evonik), catalyst (Kosmos 19 commercialized by Evonik) and distillated water.

\section{B. Proximate Analysis}

Ash content was determined as the residue after combustion in a muffle furnace at $710^{\circ} \mathrm{C}$ for $1 \mathrm{~h}$. Volatile matter was the mass fraction released when $1.0 \mathrm{~g}$ of sample was heated in a muffle furnace at $850{ }^{\circ} \mathrm{C}$ for $7 \mathrm{~min}$. The percentage of fixed carbon (FC) was the fraction that remains after subtracting the ash and the volatile matter content [14].

\section{Lignin Content (Klason Lignin)}

Klason Method was used to analyses lignin content [15]. Biomass sample $\left(300 \mathrm{mg}\right.$ ) was hydrolysed with $\mathrm{H}_{2} \mathrm{SO}_{4} 72 \%$ $(\mathrm{m} / \mathrm{v})$ for approximately $2 \mathrm{~h}$. The acid was diluted to $4 \%(\mathrm{~m} / \mathrm{v})$ and the sample was placed in an autoclave at $121{ }^{\circ} \mathrm{C}$ for $1 \mathrm{~h}$. A vacuum filtration was performed in the autoclave solution using pre-weighed crucibles. The crucible with the filtered solid was placed in an oven at $105^{\circ} \mathrm{C}$, until constant mass.

The insoluble lignin determination was performed in duplicate. Consequently, the result presented corresponds to the mean of the 4 samples results for the same condition studied. $\mathrm{Eq}(1)$ shows the calculation of the lignin insoluble percentage in biomass, where $\mathrm{m}_{1}$ corresponds to the mass in grams of the empty crucible and $\mathrm{m}_{2}$ corresponds to the mass in grams of the crucible with the filtrate, after the autoclave stage and $\mathrm{m}_{3}$ corresponds to the mass ash after 1 hour in the muffle at $650{ }^{\circ} \mathrm{C}$ [15], [16].

$$
\% \text { Insoluble Lignin }=\frac{\left(\mathrm{m}_{2}-\mathrm{m}_{3}-\mathrm{m}_{1}\right)}{0.3} \times 100
$$

\section{Holocellulose Content (Cellulose and Hemi-cellulose)}

This fraction was obtained from extractive-free biomass by means of a sodium chlorite and glacial acetic acid treatment at $70-80^{\circ} \mathrm{C}$. ASTM D-1104 standard (ASTM International, 1978) and the novel method were used for this purpose [17].

\section{E. Nitrogen Total Kjeldahl (NTK)}

The fraction of standard solution and samples were placed in the digestion tube, were added catalyst $\left(96 \% \mathrm{~K}_{2} \mathrm{SO}_{4} / 4 \%\right.$ $\left.\mathrm{CuSO}_{4} .5 \mathrm{H}_{2} 0\right)$ and concentrated sulphuric acid. The tubes were placed on the Kjeldahl digester, previously heated at 370 ${ }^{\circ} \mathrm{C}$. Heating was kept until white fumes appeared (approximately $10 \mathrm{~min}$ ), then the digestion was continued for $30 \mathrm{~min}$. The digestion residue obtained was cooled and diluted up to $10 \mathrm{~mL}$ with distilled and de-ionized water. By distillation, ammonium hydroxide was trapped as ammonium borate in a $4 \%$ boric acid solution ( $4 \mathrm{~g}$ of boric acid in $100 \mathrm{ml}$ deionized water $(w / v)$ ) and total nitrogen was determined by titration with standardized HCL. All the measurements were performed at room temperature in triplicate [18].

\section{F. Liquefaction Procedures (Polyol Synthesis)}

The liquefaction process consists of the reaction between: biomass, solvent and catalytic agent on an specific time and the heat treatment was carried out in an autoclave [19]. For each run, according to the experimental factorial design (Section 2.4), a blend of $0.5 \mathrm{~g}$ of lemon bagasse together with solvent (Crude glycerol) and Catalytic agent (Sulfuric acid 95 wt\%) was fed into the reactor (Erlenmeyer $250 \mathrm{~mL}$ ). Reactions proceeded at fixed final temperature $\left(120^{\circ} \mathrm{C}\right)$, with heating rate of $15^{\circ} \mathrm{C} / \mathrm{min}$, for a fixed time period and absolute pressure of $2 \mathrm{kgf} / \mathrm{cm}^{2}$.

The autoclave cooling and depressurizing time was about 30 minutes [20]. The product was collected for analysis and foam production according to the following sequences as shown in Fig. 1 [20].

The resulting reaction mixture was filtered to separate the residue and filtrate using ethanol to wash the residue. The residue was dried in an oven at $105^{\circ} \mathrm{C}$ during 24 hours, and the resultant solid was used to calculate the liquefaction yield (Ly), showed (Eq 2):

$$
L y(\%)=\left(\frac{\text { Biomass weight }- \text { Residue weight }}{\text { Biomass weight }}\right) \times 100
$$

where biomass weight is the lemon weight $(\mathrm{g})$ before the liquefaction process, residue weight is the insoluble lemon weight (after the liquefaction process). The liquid obtained from filtration was also dried at $75^{\circ} \mathrm{C}$ to obtain the polyols.

\section{G. Experimental Factorial Design}

The Experimental Factorial Design was performed in order to appoint an initial pattern of work. The evaluation of the reaction conditions on liquefaction yield will be performed in a further work.

The variables investigated were: catalyst amount (wt\%), time of reaction (hours) and molar ratio solvent/biomass (wt\%), as shown in Table I. The study of factors affecting the liquefaction yield was evaluated involving a multivariate factorial design with central point for three variables at two levels $\left(2^{3}\right)$.

TABLE I: LEMON BAGASSE LIQUEFACTION VARIABLES AND LEVELS USED IN THE $2^{3}$ FACTORIAL DESIGN WITH CENTRAL POINT

\begin{tabular}{llll}
\hline \hline Variables & -1 & 0 & +1 \\
\hline $\mathrm{X}_{1}$ : catalyst amount (C) & $2 \%$ & $5 \%$ & $7 \%$ \\
$\mathrm{X}_{2}$ : time of reaction (t) & $0.5 \mathrm{~h}$ & $1.0 \mathrm{~h}$ & $1.5 \mathrm{~h}$ \\
$\mathrm{X}_{3}$ : ratio solvent/biomass (R) & $2: 1$ & $3.5: 1$ & $5: 1$ \\
\hline \hline
\end{tabular}

Series of experiment of three factors and two levels: 11 experiments, as shown in Table IV of Matrix of Planning of Experiments, were conducted.

\section{H. Polyol Characterization}

\section{1) Hydroxyl number}


Polyols hydroxyl number was determined according to the ASTM D4274 standard [1], as follows: one gram of each sample of liquefied product was esterified for $20 \mathrm{~min}$ at 110 ${ }^{\circ} \mathrm{C}$ with $25 \mathrm{~mL}$ of a phthalation reagent, a mixture of $150 \mathrm{~g}$ phthalic anhydride, $24.2 \mathrm{~g}$ imidazol, and $100 \mathrm{~g}$ dioxane. Then, $50 \mathrm{~mL}$ of 1,4 dioxane and $25 \mathrm{~mL}$ of distilled water were added to this polyol mixture.

Afterwards, it was titrated with a sodium hydroxide solution $\left(1 \mathrm{~mol} . \mathrm{L}^{-1}\right)$ until the equivalence point using a $\mathrm{pH}$ meter [21]. The hydroxyl number ( $\mathrm{mg} \mathrm{KOH} / \mathrm{g}$ ) was calculated from the difference in titration of blank and the sample solutions using the following equation $\mathrm{Eq}(3)$ :

$$
\text { OH number }\left(m g \frac{K O H}{g}\right)=\frac{(B-A) N x 56.1}{W}
$$

where $\mathrm{A}$ is the volume of the sodium hydroxide solution required for titration of sample $(\mathrm{mL})$; B is the volume of blank solution $(\mathrm{mL}) ; \mathrm{N}$ is the normality of the sodium hydroxide solution and $\mathrm{W}$ is the weight of $\mathrm{LM}(\mathrm{g})$.

\section{2) FTIR (fourier transform infrared) spectroscopy}

Functional groups in the samples (in nature, solid residue, polyol and foam) were identified by FTIR spectra, obtained from a Perkin Elmer FTIR Spectrometer Frontier, with Universal ATR Sampling Accessory. The measurements were carried out within the mid-infrared area (4000 to $500 \mathrm{~cm}^{-1}$ ).

Samples were directly spread on the surface of the ATR crystal (germanium) and analyzed in transmission mode. The resolution was set to $4 \mathrm{~cm}^{-1}$, 16 scans were recorded and then corrected against the spectrum with ambient air as background. The spectra were treated by software Perkin Elmer Spectrum V 10.03.06.0100.

\section{3) Specific mass}

The specific mass was obtained by the technique of pycnometry, from the mass measurement that occupies the known volume of a pycnometer [22], using the relation presented in Equation 4.

$$
\rho=\frac{\text { biomass }(\mathrm{kg})}{\text { Pycnometry Volume }\left(\mathrm{m}^{3}\right)}
$$

\section{4) Viscosity}

The viscosities of the polyols at $25{ }^{\circ} \mathrm{C}$ were measured experimentally using Brooksfield Viscosimeter (model DV-II). The triplicate measurements were recorded with an accuracy of $\pm 0.001 \mathrm{MPa}$ s [23].

\section{Statistical Analysis}

Data obtained from responses (yield liquefaction and hydroxyl number) were submitted to a variance analysis (ANOVA) in order to evaluate the variables and interactions that are significant to the process. ANOVA was performed using Microsoft Excel software and the Electronic Spreadsheets for Calculations of Experimental Planning [24].

Hypothesis tests were performed for a confidence level of $90 \%$ and a level of significance $(\alpha)$ of $10 \%$ [24]. Results of significance were reported using Pareto Chart, prepared using Statistica 7.0 software [25]. Data were also analyzed using
Boxplot chart.

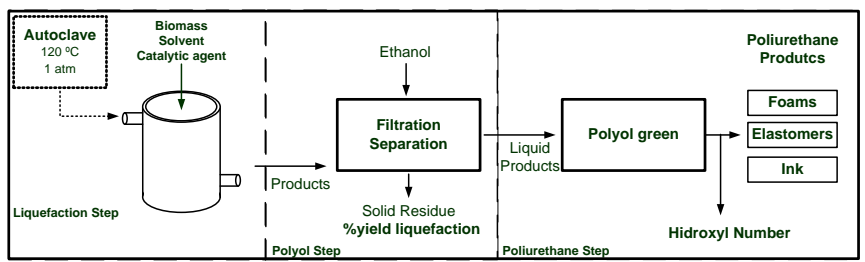

Fig. 1. Schematic flowchart by liquefaction process and foams production.

\section{RESULTS AND DISCUSSION}

The biomass liquefaction has the objective to transform carbonaceous solid materials into chemicals (as polyols), which depends on physical and chemical properties of the raw material. For this reason, proximate analysis (moisture, ash, volatile matter and fixed carbon content) estimate the use of the biomass to produce polyols, since they direct influence of the biomass composition.

The results from proximate analysis, lignin and holocelulose content and NTK are listed in Table II (\% on an oven-dry weight basis).

TABLE II: RESUlTS FOR PROXIMATE AND CHEMICAL ANALYSIS (DRY BASE) WITH THEIR RESPECTIVE STANDARD DEVIATIONS

\begin{tabular}{lccc}
\hline \hline $\begin{array}{l}\text { Parameter } \\
(\% \text { wt })\end{array}$ & Lemon Bagasse & Rice Rusk & Cassava Peels \\
\hline VM & $28.57 \pm 8.28$ & $74.08 \pm 0.63$ & $93.19 \pm 0.82$ \\
AC & $7.17 \pm 2.72$ & $12.75 \pm 0.08$ & $2.91 \pm 0.06$ \\
FCC & $68.71 \pm 9.79$ & $13.77 \pm 0.45$ & $3.31 \pm 0.84$ \\
NTK & $1.34 \pm 0.02$ & $0.38 \pm 0.02$ & $0.93 \pm 0.08$ \\
MC & $4.55 \pm 0.06$ & $5.6 \pm 1.7$ & $8.30 \pm 0.03$ \\
HC & $35.7 \pm 0.4$ & $44.7 \pm 2.5$ & $10.4 \pm 0.5$ \\
LI & $15.55 \pm 0.01$ & $31.0 \pm 2.9$ & $11.13 \pm 0.03$ \\
LS & $1.60 \pm 0.22$ & $2.26 \pm 0.03$ & $0.87 \pm 0.47$ \\
\hline \hline
\end{tabular}

VMC: Volatile Matter Content; AC: Ash Content; FCC: Fixed Carbon Content; NTK: Nitrogen Total Klason; MC: Moisture Content; HC: Holocelulose Content; LI: Lignin Insoluble; LS: Lignin Soluble

The chemical composition is also important information about the biomass, indicating as the content of carbon and hydrogen influence on the biomass liquefaction [10], [21].

Observing the results obtained for volatile matter content, it can be stated that the rice husk and cassava peels have high values of volatile material. However, the lemon bagasse presents low values of volatile material due to the mechanical process used to extract the juice. Thus, there is the reduction of volatile compounds. It was observed high content of volatile matter, which represents organic compounds of low chair that solubility rapidly, since, when exposed to heating.

The volatile matter (VM) can be considered as aromatic, pectin and flavonoid compounds (excluding moisture) that, when heated to a temperature of $493.15 \mathrm{~K}\left(120^{\circ} \mathrm{C}\right)$ can be liquefied [9], [20].

The ash content represents the inorganic compounds, which was not solubilized in the liquefaction. The lemon bagasse presented $7 \% \mathrm{wt}$, rice rusk presented $13 \mathrm{wt} \%$ and cassava peel presented $3 \%$ wt of ash content, which represent the inorganic compounds and is expected of lignocellulosic residues. Generally, high amount of ash can cause the operational problems due to the formation of inorganic complexes, which reduce the liquefaction yields (biomass 
conversion) and hydroxyl number [21], [26], [27].

Fixed or non-combined carbon (FC) is the fraction remaining after volatile matter (organic compounds of high chair). The biomass samples were observed a fixes carbon content: $69 \mathrm{wt} \%$ for Lemon bagasse; $13 \mathrm{wt} \%$ for Rice husk and $3 \mathrm{wt} \%$ for Cassava peel. The high concentration of $\mathrm{FC}$ in the lemon bagasse may be interpreted according to the structure of the carbon chain of the fruit [8].

Finally, the high nitrogen content reduces the hydrocarbon yield during thermochemical conversion, in the sample were observed lower values of nitrogen, the high concentration of nitrogen reduces the hydrocarbon yield during the thermochemical conversion. The holocellulose and lignin content (insoluble and soluble) is important parameters in considering the application of material in polyols production and PU's foam production [8].

This increase of the molar mass and hydroxyl concentration were the effects responsible for increasing of the polyols viscosity. The increased entanglement of the polymeric chains hinders slipping between chains and, moreover, the incorporated hydroxyls enhance the effects of intermolecular interactions, causing an increase in viscosity [21], [28]-[31].

The results from physical chemical properties of the raw materials for crude glycerol and polyols are listed in Table III.

TABLE III: PhySiCAL CHEMICAL PROPERTIES OF THE RAW MATERIALS FOR CRUde Glycerol aNd POLyOLS

\begin{tabular}{lcc}
\hline \hline Samples & Specific Mass $(\mathrm{g} / \mathrm{mL})$ & Viscosity $\left(\mathrm{mPa} . \mathrm{s}^{-1} \text { at } 30^{\circ} \mathrm{C}\right)^{1}$ \\
\hline Crude glycerol & $1.29 \pm 0.03$ & $115 \pm 0.23$ \\
Lemon Bagasse & $1.38 \pm 0.04$ & $150 \pm 0.01$ \\
Rice Husk & $1.31 \pm 0.02$ & $140 \pm 0.58$ \\
Cassava Peels & $1.33 \pm 0,038$ & $160 \pm 0.02$ \\
\hline \hline
\end{tabular}

The increase in biomass Specific Mass and Viscosity, compared to crude glycerol, is one of the evidences of biopolyol synthesis (Table III). Also, FTIR were used to identify functional groups and confirm the liquefaction process (Fig. 2).

Therefore, FTIR spectrum was used for the characterization of the raw materials (lemon bagasse, rice husk and cassava peels) and products resulted from bagasse and cotton stalks liquefaction as shown in Fig. 4.

The bands at approximately $3400 \mathrm{~cm}^{-1}$ correspond to the vibration of the hydroxyl groups, and the bands at approximately 2920 and $2870 \mathrm{~cm}^{-1}$ were assigned to $\mathrm{CH}_{2}$ and $\mathrm{CH}_{3}$ stretches of aliphatic chains this increase is due to the rupture in the chemical backbone of the biomass and the functionalization place on cellulose. The bands between 1750 and $1650 \mathrm{~cm}^{-1}$ corresponds to the $\mathrm{C}=\mathrm{O}$ stretching vibration in agreement with the existence of ketone, aldehyde, carboxylic, and esters groups. The bands at 1600 and $1515 \mathrm{~cm}^{-1}$ correspond to the vibration of the aromatic rings, and the bands at $1460-1420 \mathrm{~cm}^{-1}$, due to the deformation of the $\mathrm{CH}$ on the aromatic ring, were also observed in the lignin spectrum; additionally, several absorption bands were observed below $1400 \mathrm{~cm}^{-1}$, representing the contribution of various vibration modes [1], [6], [7], [21], [28]. Alcohols, ethers and esters at $1250 \mathrm{~cm}^{-1}$ and an increase and shift of the absorption in the $\mathrm{C}-\mathrm{O}$ stretching region $\left(1000-1100 \mathrm{~cm}^{-1}\right)$ at $1046 \mathrm{~cm}^{-1}$ reflects the corresponding increase in ether moieties resulting from the treatment. These absorption bands are in agreement with those published for liquefaction of several lignocellulosic materials [1], [32]. The spectra also show an important peak around $1400 \mathrm{~cm}^{-1}$, which may be attributed to inorganic compounds groups.

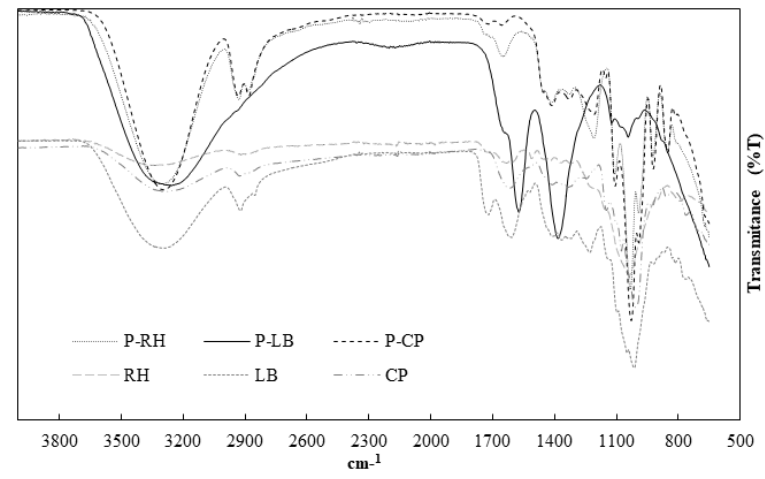

Fig. 2. Spectra of raw materials and polyol (P-RH: Polyol rice husk; P-LB: Polyol lemon bagasse; P-CP: Polyol cassava peels).

Table IV show the yield liquefaction and $\mathrm{OH}$ number results for the three biomass, this study was in agreement with the polyols requirements in view of its use in produce polyols suitable for preparation of semi-rigid and rigid polyurethane (between 300 and $1000 \mathrm{mg} \mathrm{KOH.} \mathrm{g}^{-1}$ ) [6], [7], [28], [30], [33].

Evaluating the results presented in Table IV, it was observed a high yield for the three biomass used in this study: about $88.37 \%$ for lemon bagasse; $79.02 \%$ by weight for rice husks and $91.99 \%$ by weight for cassava peels. The hydroxyl numbers and liquefaction yield obtained in this study were in the same range with those obtained during the liquefaction of different lignocellulosic materials [1], [28], [34].

It can be said therefore that the applied liquefaction conditions for lemon bagasse, rice husk and cassava peels produce green polyols appropriate for manufacture of several types of polyurethane products. The influence of the operational parameters and the biomasses characteristics on the liquefaction process will be described bellow.

From analysis of variance (ANOVA) only the catalyst was significant ( $p$-value <0.1) for the variables' responses for lemon bagasse. The factors investigated were not significant for rice husk. Evaluating the cassava peels, it was observed that the time and solvent/biomass ratio were significant for hydroxyl number. To visualize the effect of the independent variables on the evaluated responses, Pareto chart were constructed. Pareto analysis is a statistical technique used in decision-making for selecting and prioritizing a small number of items capable of producing large effect on improving processes.

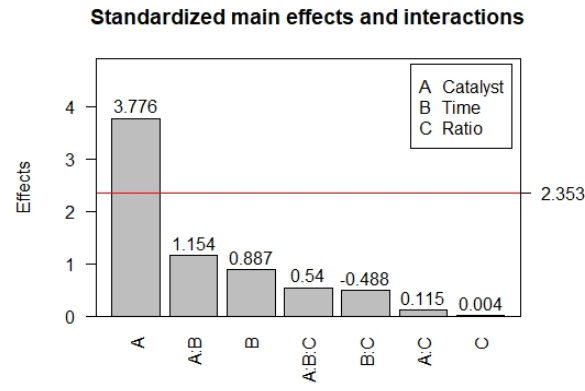

Fig. 3. Pareto plot of the standardized effects of the factors under the liquefaction yield using the Lemon bagasse. 
As shown in the Pareto chart (Fig. 3) the catalyst was the main response of the high values from the yield liquefaction for lemon bagasse.

This result was expected, since the process aims at breaking and solubilizing the solid molecules in the organic solvent. Therefore, the catalyst assists in the breaks of the carbon chains [8], [20], [31]. When, we analyses the other results, it is observed that both variables (ratio and time) and interactions were not significant to increase the yield liquefaction.

TABLE IV: PHYSICAL CHEMICAL PROPERTIES OF THE RAW MATERIALS FOR CRUDE GLYCEROL AND POLYOLS

\begin{tabular}{|c|c|c|c|c|c|c|c|c|c|}
\hline \multirow[b]{2}{*}{$\begin{array}{l}\text { Design } \\
\text { Points }\end{array}$} & \multicolumn{3}{|c|}{ Coded independent variable levels ${ }^{\mathrm{a}}$} & \multicolumn{2}{|c|}{ Lemon Bagasse } & \multicolumn{2}{|c|}{ Rice Husk } & \multicolumn{2}{|c|}{ Cassava Peels } \\
\hline & $\begin{array}{c}\text { Catalystic } \\
\text { Agent } \mathrm{X}_{1} \\
(\%)\end{array}$ & $\begin{array}{c}\text { Time } \\
\text { (hours) }\end{array}$ & $\begin{array}{c}\text { Solvent/biomass } \\
\text { ratio }(\mathrm{w} / \mathrm{w} \%)\end{array}$ & $\begin{array}{c}\text { Liquefaction } \\
\text { yield }(\%)\end{array}$ & $\begin{array}{c}\text { Hydroxyl } \\
\text { number } \\
(\mathrm{mg} / \mathrm{g})\end{array}$ & $\begin{array}{c}\text { Liquefaction } \\
\text { yield }(\%)\end{array}$ & $\begin{array}{c}\text { Hydroxyl } \\
\text { number } \\
(\mathrm{mg} / \mathrm{g})\end{array}$ & $\begin{array}{c}\text { Liquefacti } \\
\text { on } \\
\text { yield }(\%)\end{array}$ & $\begin{array}{c}\text { Hydroxyl } \\
\text { number } \\
(\mathrm{mg} / \mathrm{g})\end{array}$ \\
\hline 1 & 2 & 0.5 & $2: 1$ & 32.19 & 289.35 & 75.88 & 419.96 & 49.98 & 256.67 \\
\hline 2 & 7 & 0.5 & $2: 1$ & 65.06 & 256.12 & 35.78 & 280.60 & 88.36 & 300.30 \\
\hline 3 & 2 & 1.5 & $2: 1$ & 40.41 & 296.54 & 58.71 & 353.42 & 80.34 & 109.83 \\
\hline 4 & 7 & 1.5 & $2: 1$ & 86.52 & 795.37 & 68.51 & 440.02 & 89.69 & 475.28 \\
\hline 5 & 2 & 0.5 & $5: 1$ & 42.09 & 463.46 & 79.02 & 690.02 & 62.17 & 622.45 \\
\hline 6 & 7 & 0.5 & $5: 1$ & 65.79 & 772.46 & 65.78 & 295.17 & 59.81 & 579.48 \\
\hline 7 & 2 & 1.5 & $5: 1$ & 28.12 & 443.75 & 64.59 & 390.19 & 91.99 & 305.95 \\
\hline 8 & 7 & 1.5 & $5: 1$ & 88.37 & 829.46 & 60.51 & 375.08 & 88.27 & 105.50 \\
\hline 9 & 5 & 1.0 & $3.5: 1$ & 77.62 & 795.78 & 38.32 & 198.94 & 78.22 & 483.88 \\
\hline 10 & 5 & 1.0 & $3.5: 1$ & 55.54 & 624.99 & 53.10 & 386.94 & 84.88 & 443.46 \\
\hline 11 & 5 & 1.0 & $3.5: 1$ & 40.69 & 475.26 & 38.69 & 162.95 & 49.98 & 256.67 \\
\hline
\end{tabular}

${ }^{a}$ Refer to Table I for uncoded levels of independent variables

Standardized main effects and interactions

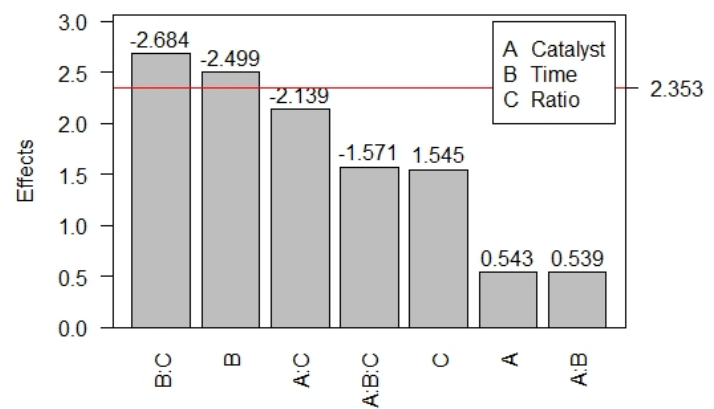

Fig. 3. Pareto plot of the standardized effects of the factors under the production of the number of hydroxyls using the Cassava peels.

A shown Pareto chart, Fig. 4, it was observed the influence of time and solvent/biomass ratio on the hydroxyls number. The hydroxyl numbers decreased with higher reaction time and ratio. The decreases in hydroxyl number are thought to be due to the complexation or repolimerizaton of the lignin with solid residues or liquefied compounds [1], [9] [35]. However, it is highlight that the hydroxyl number is an important parameter for the polyols since it determines the polyurethane product.

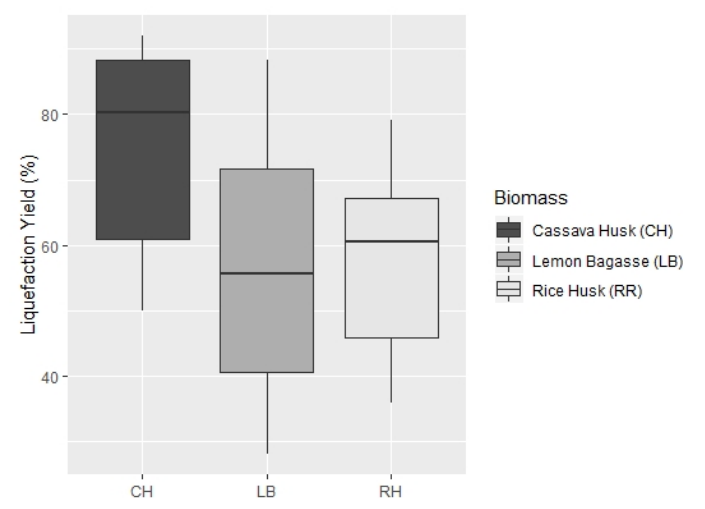

Fig. 5. Boxplot of the distribution of the liquefaction yields using the biomass Lemon Bagasse (LB), Rice Husk (RH) and Cassava Peels (CP).
Boxplot (Fig. 5) presents the average liquefaction yield of the three biomasses. It shows the higher yield for the cassava peels. Since the operational parameters were the same for all biomasses used, it can be stated that the composition influenced the yield. Cassava peel and rice husk have a higher volatile matter content.

The volatile matter represents organic compounds of low chair that solubility rapidly when exposed to heating and contribute to the liquefaction yield. Although the rice husk also presents higher amount of volatile matter, the amount of lignin and ash present in this biomass may have decreased the yield [9].

Boxplot (Fig. 6) presents the average hydroxyl number of the three biomasses. From this chart it can be seen that rice husk presented smaller variation when compared to the other biomass. In this case, regardless the operating parameters used, the hydroxyl number has a well defined range

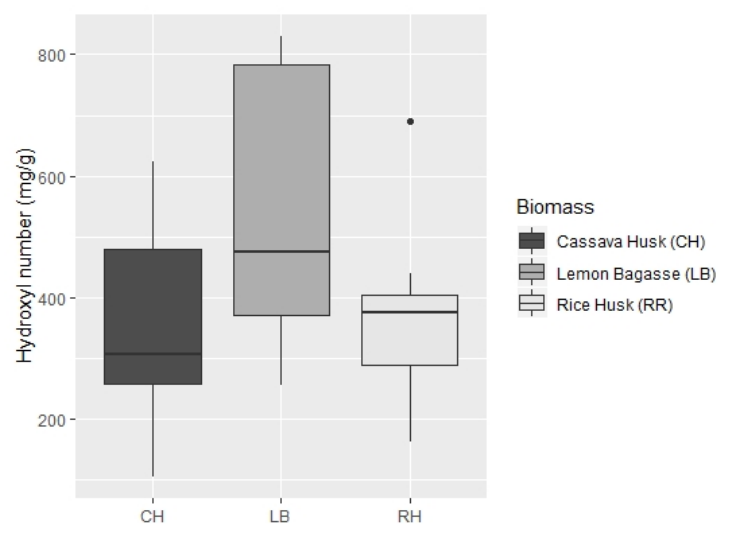

Fig. 6. Boxplot of the hydroxyl number distribution using the biomass cassava peels $(\mathrm{CH})$, lemon bagasse $(\mathrm{LB})$ and rice husk $(\mathrm{RH})$.

Lemon bagasse and cassava peel had more spread results from hydroxyl number. These results indicate hydroxyl number from these biomass can be stated according operational parameters. Hence, the liquefaction from theses biomasses can be investigated and set to fit a larger variety of 
products (foam, ink, elastomers).

\section{CONCLUSION}

Lemon bagasse, rice husk and cassava peel are suitable to produce biopolyol. From the results presented, it was observed that the composition of the lignocellulosic biomass influences the characteristics of the polyols and the yield of the process. It was also observed that among the variables investigated in this study, the catalyst was significant parameter for the yield.

\section{CONFLICT OF INTEREST}

The authors declare no conflict of interest.

\section{AUTHOR CONTRIBUTIONS}

B.S. Leite, S.A.F. Leite and B.T. Castro conducted the liquefaction process and the biomass characterization. B.S. Leite, D.J.O. Ferreira and V.F.C. Lins writing and reviewing the paper and S.A.F Leite and F.S. Bastos conducted the statistical analysis; all authors had approved the final version.

\section{ACKNOWLEDGMENT}

The present work was developed and financed in part by the Coordenação de Aperfeiçoamento de Pessoal de Nível Superior (National Council for the Improvement of Higher Education) - Brazil (CAPES) - Finance Code 001. The authors declare that they have no conflict of interest.

\section{REFERENCES}

[1] E. Hassan, M. Barbary, and M. Shukry, "Polyhydric alcohol liquefaction of some lignocellulosic agricultural residues," Industrial Crops and Products, vol. 27, no. 1, pp. 33-38, 2008.

[2] R. Janssen and D. D. Rutz, "Sustainability of biofuels in Latin America: Risks and opportunities," Energy Policy, vol. 39, no. 10, pp. 5717-5725, 2011.

[3] L. E. R. Paula, P. F. Trugilho, A. Napoli, and M. L. Bianchi, "Characterization of residues from plant biomass for use in energy generation," CERNE, vol. 17, no. 2, pp. 237-246, 2011.

[4] L. M. V. L. Mendonça, D. A. Conceição, J. Piedade, V. D. D. Carvalho, and V. C. D. A. Theodoro, "Caracterização da composição química e do rendimento dos resíduos industriais do limão Tahiti (Citrus latifolia Tanaka)," Ciência E Tecnologia de Alimentos, vol. 26, no. 4, pp. 870-874, 2006.

[5] T. Nakano, "Mechanism of thermoplasticity for chemically-modified wood," Holzforschung, vol. 48, no. 4, pp. 318-324, 1994.

[6] S. Hu, X. Luo, and Y. Li, "Polyols and polyurethanes from the liquefaction of lignocellulosic biomass," ChemSusChem, 2014.

[7] S. Hu and Y. Li, "Polyols and polyurethane foams from base-catalyzed liquefaction of lignocellulosic biomass by crude glycerol: Effects of crude glycerol impurities," Industrial Crops and Products, vol. 57, pp. 188-194, 2014.

[8] M. K. D. Rambo, F. L. Schmidt, and M. M. C. Ferreira, "Analysis of the lignocellulosic components of biomass residues for biorefinery opportunities," Talanta, vol. 144, pp. 696-703, 2015.

[9] A. Demirbaş, "Mechanisms of liquefaction and pyrolysis reactions of biomass," Energy Conversion and Management, vol. 41, no. 6, pp. 633-646, 2000.

[10] A. Dimitriadis and S. Bezergianni, "Hydrothermal liquefaction of various biomass and waste feedstocks for biocrude production: A state of the art review," Renewable and Sustainable Energy Reviews, vol. 68, pp. 113-125, 2017.

[11] V. Silva, M. A. Mosiewicki, M. L. Yoshida, M. Silva, P. M. Stefani, and N. E. Marcovich, "Polyurethane foams based on modified tung oil and reinforced with rice husk ash I: Synthesis and physical chemical characterization," Polymer Testing, vol. 32, no. 2, 2013.
[12] D. P. Wong, R. Suriyaprabha, R. Yuvakumar, V. Rajendran, Y. T. Chen, B. J. Hwang, and K. H. Chen, "Binder-free rice husk-based silicon-graphene composite as energy efficient Li-ion battery anodes," Journal of Materials Chemistry A, vol. 2, no. 33, 2014.

[13] L. Ye, J. Zhang, J. Zhao, and S. Tu, "Liquefaction of bamboo shoot shell for the production of polyols," Bioresource Technology, vol. 153, pp. 147-153, 2014.

[14] G. Rendeiro and M. Nogueira, "Combustão e Gasificação de Biomassa Sólida: Soluções Energéticas para a Amazônia,” Brasília, 2008.

[15] J. B. Sluiter, R. O. Ruiz, C. J. Scarlata, A. D. Sluiter, and D. W. Templeton, "Compositional analysis of lignocellulosic feedstocks. 1. Review and description of methods," Journal of Agricultural and Food Chemistry, vol. 58, no. 16, pp. 9043-9053, 2010.

[16] M. López, O. Huerta-Pujol, F. X. Martínez-Farré, and M. Soliva, "Approaching compost stability from Klason lignin modified method: Chemical stability degree for OM and N quality assessment," Resources, Conservation and Recycling, vol. 55, no. 2, pp. 171-181, 2010.

[17] A. Álvarez, S. Cachero, C. González-Sánchez, J. Montejo-Bernardo, C Pizarro, and J. L. Bueno, "Novel method for holocellulose analysis of non-woody biomass wastes," Carbohydrate Polymers, vol. 189, pp. 250-256, 2018.

[18] R. D. Etheridge, G. M. Pesti, and E. H. Foster, "A comparison of nitrogen values obtained utilizing the Kjeldahl nitrogen and Dumas combustion methodologies (Leco CNS 2000) on samples typical of an animal nutrition analytical laboratory," Animal Feed Science and Technology, vol. 73, pp. 21-28, 1998

[19] J. H. Lee, D. K. Kim, C. H. Park, J. H. Yu, and E. Y. Lee, "Crude glycerol-mediated liquefaction of empty fruit bunches saccharification residues for preparation of biopolyurethane," Journal of Industrial and Engineering Chemistry, vol. 34, pp. 157-164, 2016.

[20] I. Rafiqul, B. Lugang, Y. Yan, and T. Li, "Study on co-liquefaction of coal and bagasse by factorial experiment design method," Fuel Processing Technology, vol. 68, no. 1, pp. 3-12, 2000.

[21] R. Briones, L. Serrano, R. Llano-Ponte, and J. Labidi, "Polyols obtained from solvolysis liquefaction of biodiesel production solid residues," Chemical Engineering Journal, vol. 175, no. 1, pp. 169-175, 2011.

[22] F. Daniels et al., Experimental Physical Chemistry, 7th ed. McGraw Hill Book Co, N.Y., 1970.

[23] J. Esteban and M. Gonzalez-Miquel, "Thermodynamic insights on the viscometric and volumetric properties of binary mixtures of ketals and polyols," Journal of Molecular Liquids, vol. 263, pp. 125-138, 2018.

[24] R. F. Teófilo and M. M. C. Ferreira, "Quimiometria II: Planilhas eletrônicas para cálculos de planejamentos experimentais, um tutorial," Quim.Nova, vol. 29, no. 2, pp. 338-350, 2006.

[25] C. Verônica and D. C. Montgomery, "Planejamento de Experimentos Usando Statistica," Rio de Janeiro: E-Paper Serviço Editoriais, 2003

[26] G. Eriksson, H. Hedman, D. Boström, E. Pettersson, R. Backman, and M. Öhman, "Combustion characterization of rapeseed meal and possible combustion applications," Energy and Fuels, vol. 23, no. 8, pp. 3930-3939, 2009.

[27] M. F. Juhaida, M. T. Paridah, M. M. Hilmi, Z. Sarani, H. Jalaluddin, and A. R. M. Zaki, "Liquefaction of kenaf (Hibiscus cannabinus L.) core for wood laminating adhesive," Bioresour. Technol., vol. 101, pp. 1355-1360, 2010.

[28] C. S. Carriço, T. Fraga, and V. M. D. Pasa, "Production and characterization of polyurethane foams from a simple mixture of castor oil, crude glycerol and untreated lignin as bio-based polyols," European Polymer Journal, vol. 85, pp. 53-61, 2016.

[29] J. D'Souza, B. George, R. Camargo, and N. Yan, "Synthesis and characterization of bio-polyols through the oxypropylation of bark and alkaline extracts of bark," Industrial Crops and Products, vol. 76, 2015.

[30] A. Hejna, M. Kirpluks, P. Kosmela, U. Cabulis, J. Haponiuk, and $Ł$. Piszczyk, "The influence of crude glycerol and castor oil-based polyol on the structure and performance of rigid polyurethane-polyisocyanurate foams," Industrial Crops and Products, vol. 95, pp. 113-125, 2017.

[31] N. Mahmood, Z. Yuan, J. Schmidt, and C. Xu, "Depolymerization of lignins and their applications for the preparation of polyols and rigid polyurethane foams: A review," Renewable and Sustainable Energy Reviews, vol. 60, pp. 317-329, 2016.

[32] K. Giannakopoulou, M. Lukas, A. Vasiliev, C. Brunner, and H. Schnitzer, "Conversion of rapeseed cake into bio-fuel in a batch reactor: Effect of catalytic vapor upgrading," Microporous and Mesoporous Materials, vol. 128, no. 1-3, pp. 126-135, 2010. 
[33] A. Kairyte and S. Vejelis, "Evaluation of forming mixture composition impact on properties of water blown rigid polyurethane (PUR) foam from rapeseed oil polyol," Industrial Crops and Products, vol. 66, 2015.

[34] S. A. F. Leite, B. S. Leite, C. S. Carriço, A. T. P. Dell'Isola, and J. V. H. Dangelo, "Characterization of biomass residues aiming energy and by-Products generation," Chemical Engineering Transactions, vol. 65, pp. 733-738, 2010.

[35] Y. Yao, M. Yoshioka, and N. Shiraishi, "Water-absorbing polyurethane foams from liquefied starch," J. Appl. Polym. Sci., vol. 60, pp. 1939-1949, 1996.

Copyright $\odot 2019$ by the authors. This is an open access article distributed under the Creative Commons Attribution License which permits unrestricted use, distribution, and reproduction in any medium, provided the original work is properly cited (CC BY 4.0).

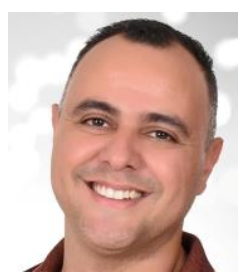

Leite B. S. was born in Brazil in 1981, graduated in industrial chemistry from the Vale do Rio Doce University - UNIVALE in 2002, in the year of 2008 he obtained a master's degree in chemical engineering from the Federal University of Minas Gerias - UFMG, in 2012 he obtained the title of PhD in chemical engineering from the State University of Campinas.

Since 2010, he has worked as professor at the Federal University of Viçosa, Campus Florestal (UFV- Campus Florestal). He has experience in Chemistry, with emphasis on chemical physics, working in the area of chemical and computer processes and in the mining and pulp and paper production sector. He is currently developing his research in agro industrial waste use with the objective of producing new materials and energy.

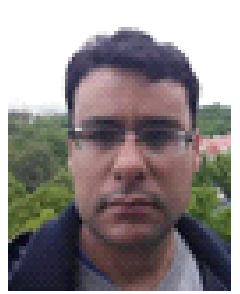

Ferreira D. J. O. was born in Belo Horizonte, Brazil, on July 20, 1981. Graduated in chemical engineering at Federal University of Minas Gerais (UFMG) - Belo Horizonte, Minas Gerais, Brazil; 2005; MSc. in chemical engineering at Federal university of Minas Gerais (UFMG) - Belo Horizonte, Minas Gerais, Brazil; 2007; PhD. in chemical engineering at University of São Paulo (USP) - São Paulo, São Paulo, Brazil; 2012. His major field of study: Use of Computational Fluid Dynamics (CFD) for evaluation of combustion and transformation processes involving biomass.

Dr. Ferreira has been working as associate post-doctoral researcher at Chemical Engineering Department of UFMG, Brazil since 2016, which the main research is about the study of the influences of reactive in stainless corrosion pipeline in a biodiesel production plant. Previously he had worked with biomass combustion in two different boilers: burning of sugar cane bagasse in grate boiler and black liquor in Kraft recovery boiler.

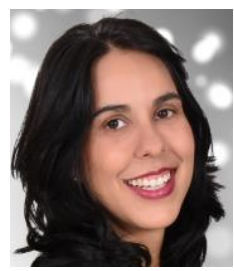

Leite S. A. F was born in Brazil in 1982. She got the $\mathrm{Ph} . \mathrm{D}$. in chemical engineering from the State University of Campinas; the master in chemical engineering, Federal University of Minas Gerais (UFMG). She is specialist in environmental education, SENAC-MG and chemistry graduate, also by UFMG Since 2009, she has worked as professor of the environmental technology management at the Federal University of Viçosa, Campus Florestal (UFV- Campus Florestal).

She works at the university develops extension and research activities, which stand out as leaders focused on the evaluation of performance in water systems, the work solution and the treatment and valorization of the biomass generated in agricultural processes.

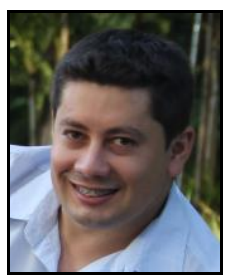

Bastos F. S. has a degree in mathematics (UFV), the master in applied statistics and biometrics (UFV) and the doctor in statistics (UFMG). He is currently adjunct professor II of the Federal University of Viçosa-Campus UFV Florestal and is interested in the following subjects: Probability, regression models, sampling selection models and applications.

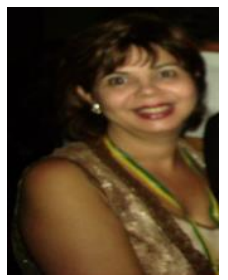

Lins V. F. C. was born in Brazil, graduate at Engenharia Química from Universidade Federal de Minas Geras (1980), the master's at material and metallurgical engneering from Universidade Federal de Minas Gerais (1987) and Ph.D. at material and metallurgical engineering from Universidade Federal de Minas Gerais (1994). Has experience in material and metallurgical engineering, focusing on corrosion, acting on the following subjects: corrosão, corrosão atmosférica, poli(tereftalato de etileno), liga fe-mn-al-si-c and eletrólise.

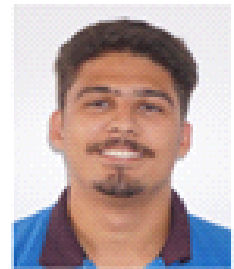

Castro B. T. was born in Brazil in 1997. He is a chemistry student at the Federal University of Viçosa, Campus Florestal (UFV- Campus Florestal). 